\title{
Evidence of stretching of the lithosphere under Denmark
}

\author{
Søren Gregersen, Lene Vandur Nielsen and Peter Voss
}

The structure of the lithosphere under Denmark has been investigated in relation to adjacent regions of Sweden and Germany. The most interesting result of the study is that the $120 \mathrm{~km}$ thick lithosphere under Denmark appears to be a stretched version of the Swedish lithosphere, which is more than twice as thick. During the international project Teleseismic Tomography across the Tornquist Zone (Tor), field work and international interpretation were carried out between 1996 and 2002. Following the field work period, modelvelocity computations were undertaken based on observations of distant earthquakes (e.g. Arlitt 1999; Shomali et al. 2002; Voss et al. 2006), and recently an evaluation of the Tor results was completed (Nielsen 2007).

The Tor project investigates deeper parts of the Earth than previous projects, and in particular the depth interval $50-300 \mathrm{~km}$, which is below the crystalline crust. The investigations have included many geophysical features such as teleseismic P-wave tomography, Rayleigh wave velocities, shear wave splitting and wave scattering. We have distinguished between relatively high- and low-velocity zones, which also show variations in anisotropy and scatter characteristics. Generalised high-velocity zones correspond to the lithosphere, while generalised relatively low-velocity zones are equivalent to the asthenosphere.

The main outcome of the combined studies is that the deep lithosphere can be divided into three blocks separated approximately along the national boundaries between Sweden and Denmark and between Denmark and Germany. The boundaries between the blocks are steep, almost vertical. The Denmark block has lithosphere properties between those to the north and south. Based on previous crustal studies and the Tor results, we suggest that the Denmark block has evolved by stretching. The details in the new evaluation are derived from teleseismic tomography. Here we present a synthesis of the many derived models in the light of the new evaluation.

\section{Lower lithosphere: data and interpretation}

The area of investigation is shown in Fig. 1 and examples of analyses of P-wave data are presented in Fig. 2. The first and most important part of the data treatment is correction for the rather well-known structure of the crust, see Fig. 2, middle frames (e.g. EUGENO-S working group 1988; Thybo
2000). The end products of the analyses are two patterns of travel-time residuals for the lower lithosphere (bottom frames of Fig. 2). Together with approximately 50 similar patterns of P-wave travel-time residuals, each for one earthquake, these constitute the data for the model-velocity computations.

Several tomographic velocity calculations have been made in 2-D cross-sections along the line of seismographs shown in Fig. 1 (e.g. Arlitt 1999; Busche 2001; Shomali et al. 2002; Nielsen 2007). The results of Nielsen's (2007) work are shown in Figs 3 and 4, which are, respectively, a cross-section with P-wave velocity deviations from a laterally homogeneous Earth, and the horizontal gradients of these P-wave velocities. Figure 4 pinpoints the sharpest boundaries between different lithosphere/asthenosphere characteristics.

The teleseismic tomography has a poor resolution in the upper $50 \mathrm{~km}$ of the Earth, and the interval from 0 to $50 \mathrm{~km}$

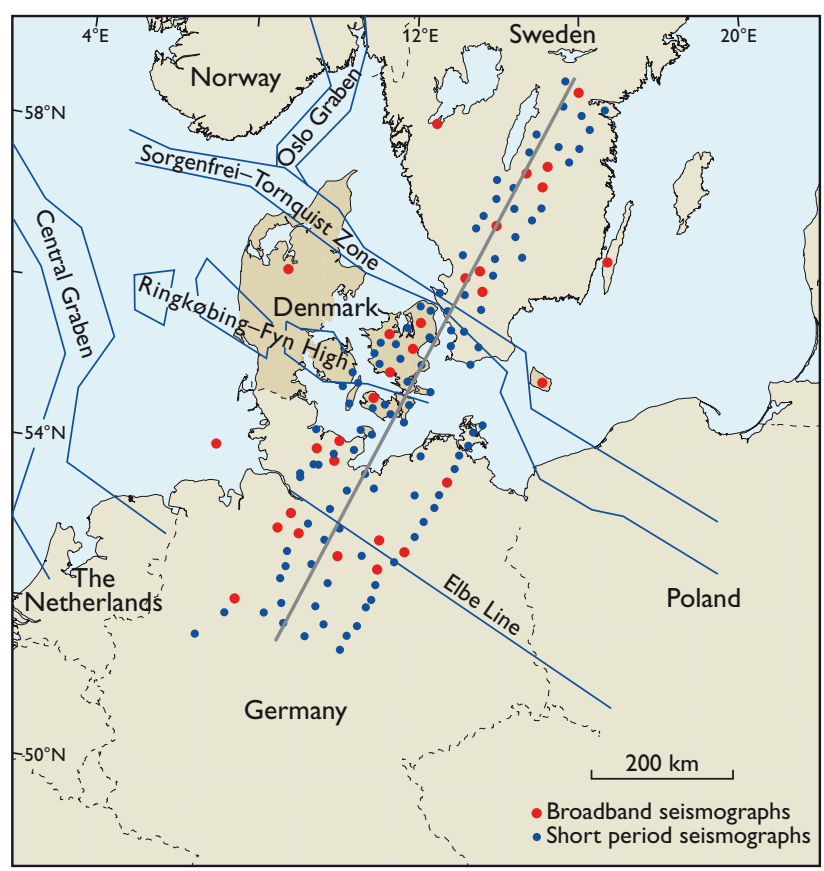

Fig. 1. The location of seismographs during field work of the Tor project 1996-1997. The 2-D interpretation profiles of Figs 3 and 4 follow the line in the middle of the cloud of seismographs from $59^{\circ} \mathrm{N}, 16^{\circ} \mathrm{E}$ to $51^{\circ} \mathrm{N}, 9^{\circ} \mathrm{E}$, crossing the Sorgenfrei-Tornquist Zone at a right angle. The Ringk $\varnothing-$ bing-Fyn High is a basement high separating sedimentary basins to its north and south. The Elbe Line is a geophysically recognised lineament. Other important broad-scale features are the Permian Oslo Graben and the Mesozoic Central Graben. 
Fig. 2. P-wave travel time residuals from two earthquakes, in Japan $\left(19\right.$ October $1996,32^{\circ} \mathrm{N} 132^{\circ} \mathrm{E}$, wave arrival to Tor area from north-east) and in Mexico (11 January 1997, $18^{\circ} \mathrm{N} 103^{\circ} \mathrm{W}$, wave arrival to Tor area from north-west), each in one column. For each of the earthquakes the upper diagram shows total observed residuals (observed arrival times minus expected arrival times according to the global average tables IASP91). The middle diagram shows computed crustal residuals to $50 \mathrm{~km}$ depth (from Pedersen et al. 1999), which, when subtracted from the observed ones, yield the lower lithosphere residuals below $50 \mathrm{~km}$ depth which are shown in the lower diagram (from Pedersen et al. 1999).

depth is not shown on Figs 3 and 4. However, many previous investigations based on other data have provided rather detailed information about shallower structures (Arlitt et al. 1999; Pedersen et al. 1999). A dipping crustal transition from the Baltica crust in the north-east to the Avalonia crust in the south-west has been interpreted in the broad box A area. The blue and red $\mathrm{P}$-velocity anomalies are computed with reference to a one-dimensional global travel-time model. Two sharp and steep velocity changes, or red to blue steps, are seen in Figs 3 and 4, and are outlined by boxes B and C. A third step at $57^{\circ} \mathrm{N}$, seen as a colour change from light blue to dark blue, which was discussed by Gregersen et al. (2006), may not be significant (Fig. 4). The uncertainties of the exact locations of the transitions and their slopes are illustrated by the sizes of the boxes ( $\mathrm{B}$ and $\mathrm{C})$ in the transition regions.

A low-velocity asthenospheric layer, as deduced from higher mode surface-wave studies mentioned by Gregersen $e t$ al. (2006), is indicated by box D. This low-velocity layer does not extend to the north-east. This is consistent with the earlier interpretation of fundamental mode Rayleigh waves that showed absence of low-velocity asthenospheric layers below the Baltic Shield at this depth (Cotte et al. 2002).

It can be difficult to evaluate which features in the models should be regarded as well defined and appropriate to interpret in geological terms. Issues of spatial resolution, accuracy and uniqueness of the models are important. Within the Tor project considerable efforts have therefore been dedicated to examining these issues using, for example, tomographic inversions. In such an inversion it is straightforward to calculate the variance of model parameters, which quantifies the reliability of each parameter. This variance of a model parameter has only limited value, partly because mathematical
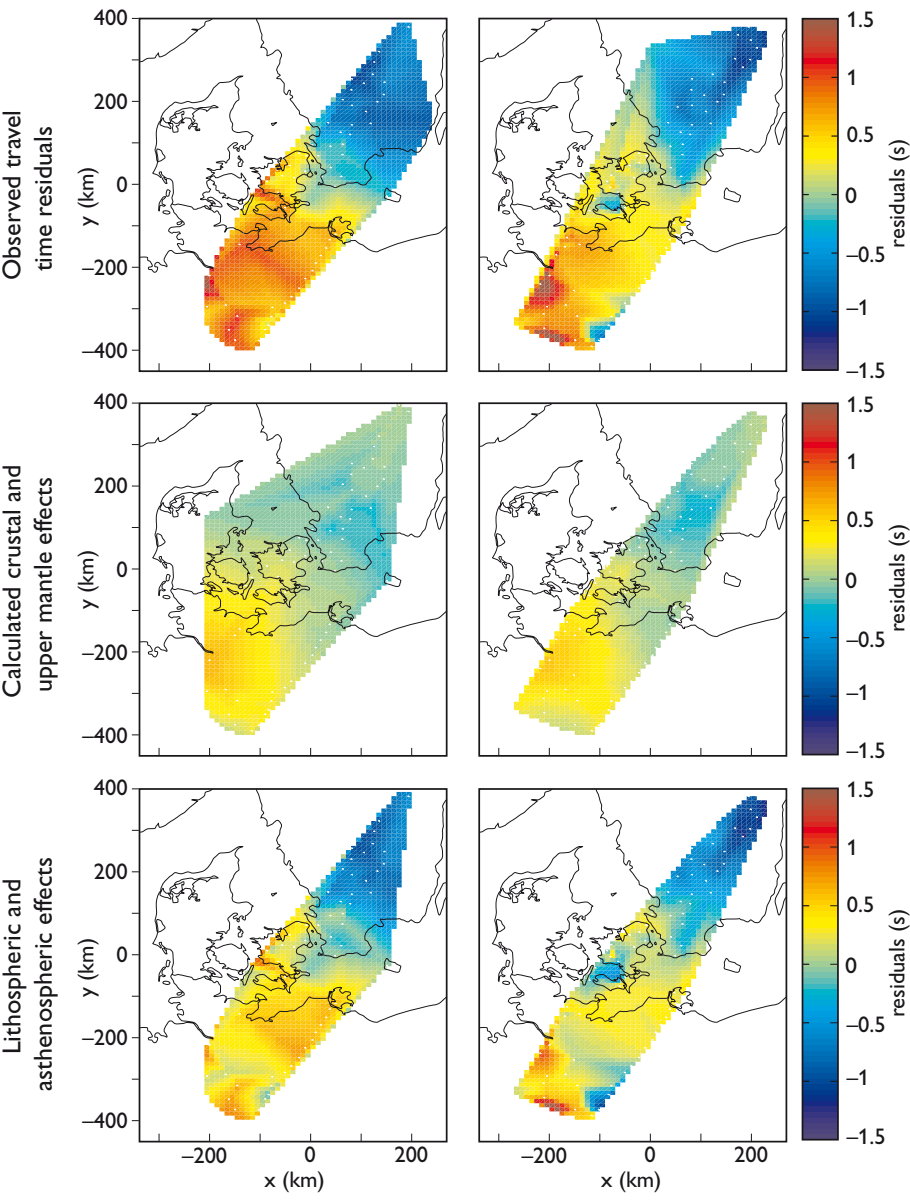

assumptions of linearity are simplified, and partly because the often complicated interactions between model parameters are ignored.

The estimation of resolution also depends on choices in the mathematical inversion procedure. The resolution is limited by station spacing, ray geometry between earthquakes and seismic stations, and the frequency content of data, and it is different for various parts of the model. These complex problems mean that different approaches must be considered to quantify reliability. This has been carried out in previous analyses and evaluated by Nielsen (2007).

\section{Suggested evolution of the lithosphere under Denmark}

The broad-scale division of the lithosphere into three different blocks, with Denmark as the middle one of intermediate structure, has been confirmed by several studies. One major outcome of the Tor project is therefore unquestionably that the Sorgenfrei-Tornquist Zone is connected to a very deep and prominent lithospheric velocity difference (box $\mathrm{C}$ in Figs 3 and 4). Another marked change in lithosphere-asthenosphere properties is found in the depth range 0-120 km between the southern part of the Ringkøbing-Fyn High and 


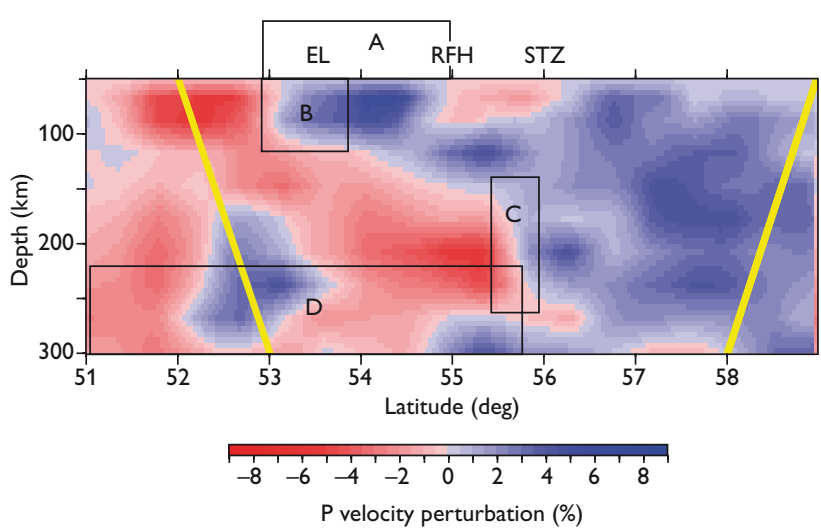

Fig. 3. Tomographic image of the lithosphere/asthenosphere system in a profile along the Tor array from $59^{\circ} \mathrm{N}, 16^{\circ} \mathrm{E}$ to $51^{\circ} \mathrm{N}, 9^{\circ} \mathrm{E}$. Blue colours are areas with high $\mathrm{P}$-wave velocities, while red colours are areas with low Pwave velocities with respect to the laterally homogeneous IASP91 model (Kennett \& Engdahl 1991). The boxes show the uncertainty around the lateral changes (see text). STZ, Sorgenfrei-Tornquist Zone; RFH, Ringkøbing-Fyn High; EL, Elbe Line.

the Elbe Line (boxes A and B in Figs 3 and 4). These interpretations together with the well-known surface geology and crustal structure (e.g. EUGENO-S working group 1988; Thybo 2000) have been discussed at many Europrobe meetings. The outcome of these discussions is that the evolution of the lithosphere-asthenosphere system can be summarised in graphical form (Fig. 5), with collision, spreading, shearing and compression over the last 500 million years.

Based on the Tor-project studies by Cotte et al. (2002) and Gregersen et al. $(2002,2006)$ we suggest that together with the other geophysical data the surface wave results and the tomography results (Figs 3 and 4) indicate a lithosphere thickness of a little less than $100 \mathrm{~km}$ in the south-western part of the profile, a little over $100 \mathrm{~km}$ in the middle, and a lithosphere thickness of more than $200 \mathrm{~km}$ in the north-eastern part of the region. The Baltic Shield in Sweden, i.e. the part of the craton exposing old, Precambrian crystalline rocks, terminates to the south-west at the Sorgenfrei-Tornquist Zone. From deep drilling data and seismic crustal studies, it is deduced that material originating from the craton extends southwards from the Sorgenfrei-Tornquist Zone, gradually thins where overlying sediments are thick and terminates just south of the Ringkøbing-Fyn High. In the late Precambrian to early Palaeozoic (c. $600 \mathrm{Ma}$ ), the eastern European craton including the Baltic Shield formed the core of the palaeo-continent Baltica, and the Tor study region was a passive continental margin.

The tomographic images reveal the structure originating from this episode, reworked by a number of later events, as illustrated by Fig. 5. The evolution can be divided into four stages. During stage 1 two separate lithospheric plates collided in late Palaeozoic times. In stage 2 the area was deformed by

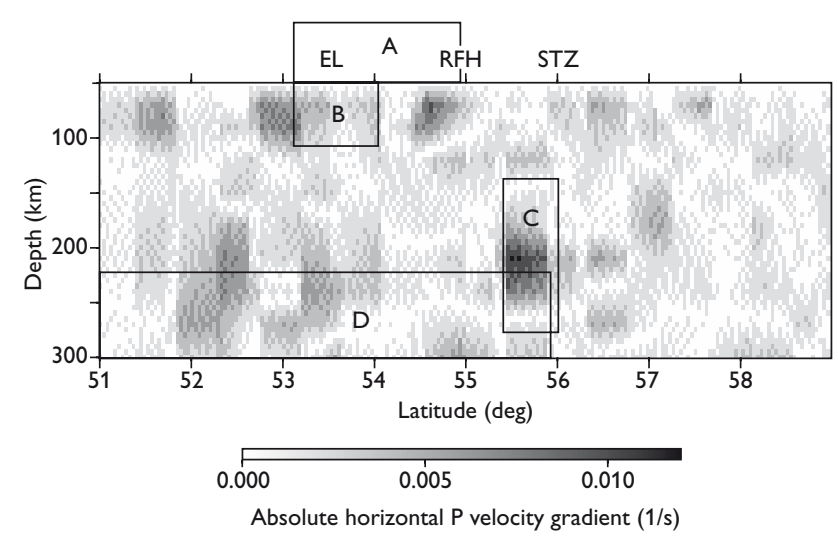

Fig. 4. Tomographic image along the Tor array. For location see Fig. 1. Dark areas show the largest horizontal gradients in P-wave velocities, corresponding to large changes in material. The boxes show the uncertainty around the lateral changes (see text).

lithospheric stretching and transcurrent faulting, the Ringkøbing-Fyn High with its thick crust was detached from the Baltic craton, and the various blocks of the Ringkøbing-Fyn High rotated slightly. In the ensuing stage 3, lithospheric stretching was perpendicular to the trend of the plate transition and the Ringkøbing-Fyn High. The compressional stage 4 is very different, involving inversion of the Sorgenfrei-Tornquist Zone.

\section{Conclusions}

Our essential contributions from geophysics to the geological evolutionary account are the measurements of crustal and lithospheric thinning. In previous studies of the crustal structure (EUGENO-S working group 1988) it was suggested that the crust in Denmark between the Sorgenfrei-Tornquist Zone and the Ringkøbing-Fyn High had been stretched during the late Palaeozoic and the Mesozoic. Preliminary modelling of the stretching of the sedimentary basins and the crystalline crust has been carried out by Nielsen \& Balling (1990). Fuller modelling, including the entire lithosphere, has been undertaken by Frederiksen et al. (2001). Since the results of the Tor project also show a distinct thinning of the lower lithosphere from the Swedish to the Danish area, we see this as evidence of essentially full lithospheric stretching. The reasoning has developed historically from recognition of stretching in sedimentary basin evolution, and then stretching of the crust (EUGENO-S working group 1988), to the present claim of stretching of the entire lithosphere. This account can now be reversed in a well-founded story of cause and effect: the lithosphere is stretched, and the crystalline crust is thereby stretched, creating the sedimentary basins. 
Fig. 5. Generalised summary diagram of the large-scale geological development of the Tor area (Fig. 1). Blue shows areas with sediments, orange shows areas of crystalline crust, and red is the uppermost mantle lithosphere. The Sorgenfrei-Tornquist Zone (STZ) and the Ringkøbing-Fyn High (RFH) act through time as compression, spreading and shearing zones. The arrows show the regional stress field (from Gregersen et al. 2006).

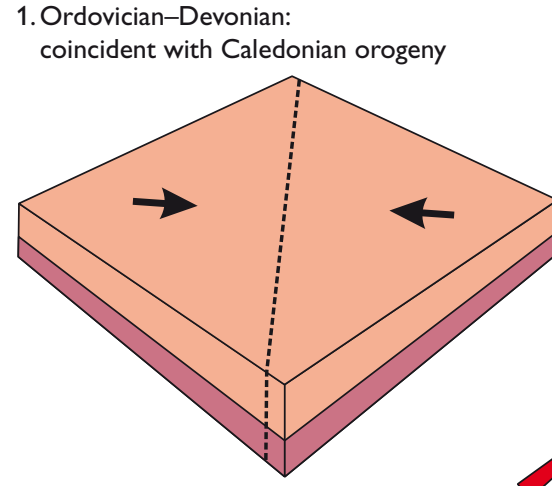

2. Late Carboniferous - early Permian: coincident with Variscan orogeny

3. Triassic-Jurassic: lithospheric stretching

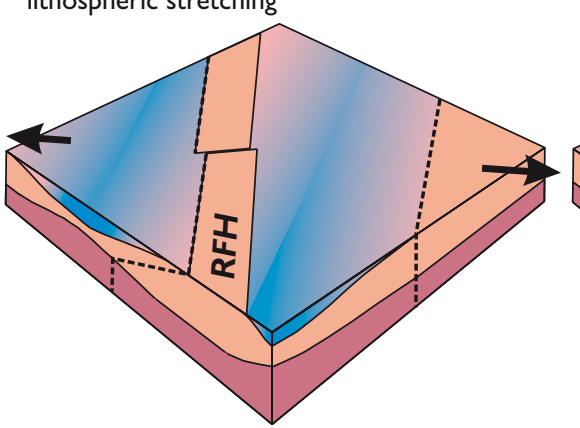

4. Late Cretaceous - early Cenozoic: coincident with alpine orogeny

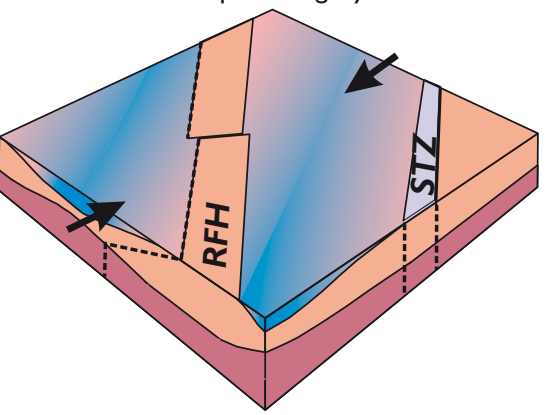

\section{References}

Arlitt, R. 1999: Teleseismic body wave tomography across the TransEuropean Suture Zone between Sweden and Denmark, 109 pp. Unpublished Ph.D. thesis, Swiss Federal Institute of Technology, Zurich, Switzerland.

Arlitt, R., Kissling, E., Ansorge, J. \& TOR Working Group 1999: 3-D crustal structure beneath the TOR array and effects on teleseismic wavefront. Tectonophysics 314, 309-319.

Busche, H. 2001: Manteltomographie: Verspätungen von Wellenzügen im Norddeutsch-Dänischen Becken, 105 pp. Unpublished Ph.D. thesis, Christian-Albrechts-Universität Kiel, Germany.

Cotte, N., Pedersen, H.A. \& Tor Working Group 2002: Sharp contrast in lithospheric structure across the Sorgenfrei-Tornquist Zone as inferred by Rayleigh wave analysis of TOR 1 project data. Tectonophysics $\mathbf{3 6 0}$, 75-88.

EUGENO-S working group 1988: Crustal structure and tectonic evolution of the transition between the Baltic Shield and the north German Caledonides (The EUGENO-S Project). Tectonophysics 150, 253-348.

Frederiksen, S., Nielsen, S.B. \& Balling, N. 2001: A numerical model for the Norwegian-Danish Basin. Tectonophysics 343, 165-183.

Gregersen, S., Voss, P., Shomali, Z.H. \& Tor Working Group 2002: Summary of Project Tor: Delineation of a stepwise, sharp, deep lithosphere transition across Germany-Denmark-Sweden. Tectonophysics 360, 61-73.

Gregersen, S., Voss, P., Shomali, Z.H., Grad, M., Roberts, R.G. \& Tor Working Group 2006: Physical differences in the deep lithosphere of northern and central Europe. In: Gee, D.G. \& Stephensson, R.A. (eds): European lithosphere dynamics. Geological Society Memoirs (London) 32, 313-322.
Kennett, B.L.N. \& Engdahl, E.R. 1991: Traveltimes for global earthquake location and phase identification. Geophysical Journal International 105, 429-465.

Nielsen, L.V. 2007: Teleseismic P wave tomography across the Sorgenfrei-Tornquist Zone. Evaluation of Tor project results, 109 pp. Unpublished cand. scient. thesis, University of Copenhagen, Denmark.

Nielsen, S.B. \& Balling, N. 1990: Modelling subsidence, heat flow, and hydrocarbon generation in extensional basins. First Break 8, 23-31.

Pedersen, T., Gregersen, S. \& Tor Working Group 1999: Project Tor: Deep lithospheric variation across the Sorgenfrei-Tornquist Zone, southern Scandinavia. Bulletin of the Geological Society of Denmark 46, 13-24.

Shomali, Z.H., Roberts, R.G. \& Tor Working Group 2002: Non-linear body wave teleseismic tomography along the TOR array. Geophysical Journal International 148, 562-574.

Thybo, H. 2000: Crustal structure and tectonic evolution of the Tornquist Fan region as revealed by geophysical methods. Bulletin of the Geological Society of Denmark 46, 145-160.

Voss, P., Mosegaard, K., Gregersen S. \& TOR working group 2006: The Tornquist Zone, a north-east-inclining lithospheric transition at the south-western margin of the Baltic Shield: revealed through a non-linear teleseismic tomographic inversion. Tectonophysics 416, 151-166.

\section{Authors' addresses}

S.G. \& P.V., Geological Survey of Denmark and Greenland, Øster Voldgade 10, DK-1350 Copenhagen K, Denmark. E-mail: sg@geus.dk L.V.N., Niels Bohr Institute, University of Copenhagen, Juliane Maries Vej 30, DK-2100 Copenhagen Ø, Denmark. 